\title{
The role of children's food packaging characteristics on parent's purchasing decision
}

\author{
Naser Azad $^{\mathrm{a}}$, Mojtaba Rafiee ${ }^{\mathrm{b}}$ and Leila Hamdavipour ${ }^{\mathrm{c}^{*}}$
}

${ }^{a}$ Department of Management, Islamic Azad University, South Tehran Branch, Tehran, Iran

${ }^{b}$ PayamNoor University, Iran

${ }^{c}$ Department of Management, Islamic Azad University, Arak Branch, Arak, Iran

ART I C L E I NF O A B T T A C T

Article history:

Received October 1, 2011

Received in Revised form

November, 14, 2011

Accepted 15 November 2011

Available online

7 December 2011

Keywords:

Advertisement

Packaging advertisement

Effectiveness

Marketing planning
Packaging is one of the most important parts of marketing planning and it plays a key role on marketing products and services. A good packaging absorbs more customers and increases people's intention on purchasing products. In this paper, we study the relationship between packaging food products produced for children and parents' intentions to purchase these kinds of products. The paper uses a questionnaire based on Likert scale, distributes 392 questionnaires among the target population of this survey who are one of the well-known food chain suppliers named Shahrvand, and collects 381 filled questionnaires. There are three hypotheses for the proposed study of this paper. The first hypothesis assumes there is a meaningful relationship between packaging children's food characteristics and parents' intention on purchasing product. The second hypothesis studies the relationship between children food packaging and the parent's priority purchasing decision and the third hypotheses examines the relationship between children food selection and the parent's purchasing decision. The results confirm all three hypotheses and provide evidence that a suitable packaging for children's food product have important impact on parents' intention for purchasing products.

\section{Introduction}

Packaging food products is one of the most important parts of marketing in today's business environment. There are many steps along the manufacturing process taken into account in the design of a package for any given food product. There are many product developments involved for packaging a product such as research \& development, manufacturing, marketing, graphic design, regulatory, purchasing, planning, etc. During the past few years, there have been significant works on investigating the effects of packaging on products and services. Becker et al. (2011) examined the effect of packaging design on taste impressions and their study revealed that shape curvature and color saturation may impact more general product evaluations and price expectations. Ho and Oh (2009) investigated the application of e-security seals on web sites and their relative impact on e-

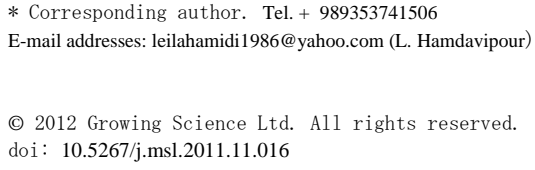


commerce firm reputation by affecting customers' perceptions of trust in a service provider. They gathered some necessary data from 211 web users and reported that 106 respondents were cognitive and affective of e-security seals. The results also explained further clarification of the relationship between e-security seals and sales effectiveness and the findings pointed towards a positive belief by consumers in e-security seals.

Gofman et al. (2010) studied different approaches to consumer-driven optimization of package design. Ha et al. (2010) performed a detailed survey for the satisfaction consequences in repurchase situations based on some empirical studies and explained that psychological mediators were useful when repurchase situations were taken into account. Kauppinen-Räisänen and Luomala (2010) studied the impact of package colors in consumers' product experiences by studying the relationship between color meanings and product. They also investigated the meanings associated with colors in a product context. Morgado (2008) presented a case associated with plastics packaging company in Portugal integrates itself into the value chain of company clients. They looked for assessing various objectives including a case of success in technological, processes and business innovation. They presented a case of success in business strategy, based on the build-up of partnerships to build a platform for discussion of a first mover strategy.

Oliveira et al. (2010) investigated characterization of the domestic usage of food packaging in terms of amount and type at the household level. They chose all the necessary data such as design, methodology, and approach from a sample of Portuguese consumers. The results achieved were analyzed, which were associated with the current assumptions made for the safety assessment of materials based on European legislation. Rubdh (2009) studied an investigation to find out how packaging and packaging design could contribute to competitive advantage for marketing a consumer product. Rundh studied the effects of different factors on the design process of a package from external and internal factors where the outcome of the design process was associated with the interaction between the main actors in this process.

Silayoi and Speece (2007) studied on understanding consumer behavior for purchasing decisions based on packaging specifications. They reported that visual package elements play a major role, representing the product for many consumers, especially when they do not want to spend much time. Vernuccio et al. (2010) examined an exploratory study of marketing, logistics, and ethics in packaging innovation. They explained that simultaneous integration among marketing, logistics and ethics recurs in only one third of the cases.

Wells et al. (2007) studied the relevance importance of packaging design for own-label food brands. The study showed that there was a strong association regarding the influence of packaging on the purchase decision. Williams et al. (2008) investigated a life cycle perspective on environmental effects of customer focused packaging development. The study showed the possibilities of increasing customer satisfaction and reducing the environmental effect from food-packaging systems in a life cycle perspective using results from a study on consumers' demands on packaging based on Kano's theory of attractive quality. They reported that there were some potentials to increase customer satisfaction and at the same time decrease in the environmental impact of the food-packaging system, especially when the packaging design assists to reduce food losses. Ogba and Johnson (2010) investigated on how packaging affects the product preferences of children and the buyer behavior of their parents in the food industry.

In this paper, we present an empirical study to learn about the impact of packaging on customer's attraction. The orientation of this paper first presents details of our survey in section 2 and then it presents the results of our survey in section 3. The concluding remarks are given in the last to summarize the contribution of this paper. 


\section{The proposed study}

The proposed study of this paper uses a questionnaire to gather customers' opinion on how packaging impacts customer's attraction on purchasing a food product. The survey studies three main hypotheses; the first hypothesis assumes there is a meaningful relationship between packaging children's food characteristics and parents' intention on purchasing product. The second hypothesis studies the relationship between children food packaging and the parent's priority purchasing decision and the third hypotheses considers the relationship between children food selection and the parent's purchasing decision. The second and the third hypotheses study the indirect impact of packaging children's food characteristics on purchasing food products. There are literally different factors influencing children's intention on food product such as age, decision-making stage, the impact of food product on other people's perception, gender, family and their relationships. Children normally cry or produce aggressive behavior to persuade their parents for buying a particular toys or products and this kind behavior normally works well.

\subsection{Sample size}

In this paper, the population of the survey includes the people who purchase from a well-known chain called Shahrvand located in different parts of the capital city of Iran, Tehran. Since the size of the population is relatively large, a sampling technique has been used. The number of initial sampling was set to 30, which yields $\sigma^{2}=0.081$ when the error is 0.05 . Therefore, we have $n=\frac{Z_{\alpha}^{2} \sigma^{2}}{d^{2}}=\frac{1.96^{2} \times 0.128}{0.05^{2}}=196$. In this survey, the number of sample size is set to 392, which is twice as many as the initial calculated sample size. We have used SPSS software package (Levesque, 2007) to perform the computations and the reliability of the survey for a small sample size of 35 is 0.846 , which means the questionnaire is highly reliable.

\subsubsection{Characteristics of the participants}

In our survey, $45.9 \%$ of the participants were men and $54.1 \%$ were women. In terms of the number of children, we have divided the survey people into four groups and $44.88 \%$ of the survey people had only one child, 38.58\% had two children, 9.45\% took care of three children and only $7.09 \%$ of the survey people had more than four children. Fig. 1 shows distribution of the number of children of the survey participants.

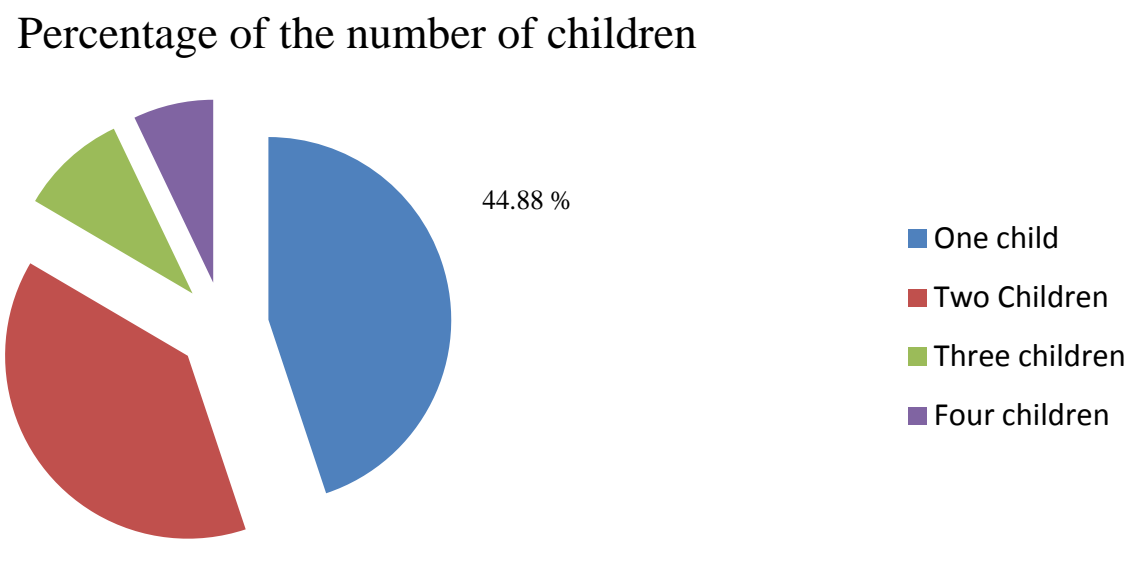


Fig. 1. The frequency of the number of children

In terms of the children's age, 20.73\% of the participants had children between 3 to 6 years old, $25.46 \%$ of them were taking care of children aged between 6 to 9 years, $27.82 \%$ of the survey people were keeping children aged between 9 to 11 years and the remaining 25.98\% belongs to people who had teenagers aged between 11 to 14. Fig. 2 demonstrates details of the survey people in terms of their children's age.

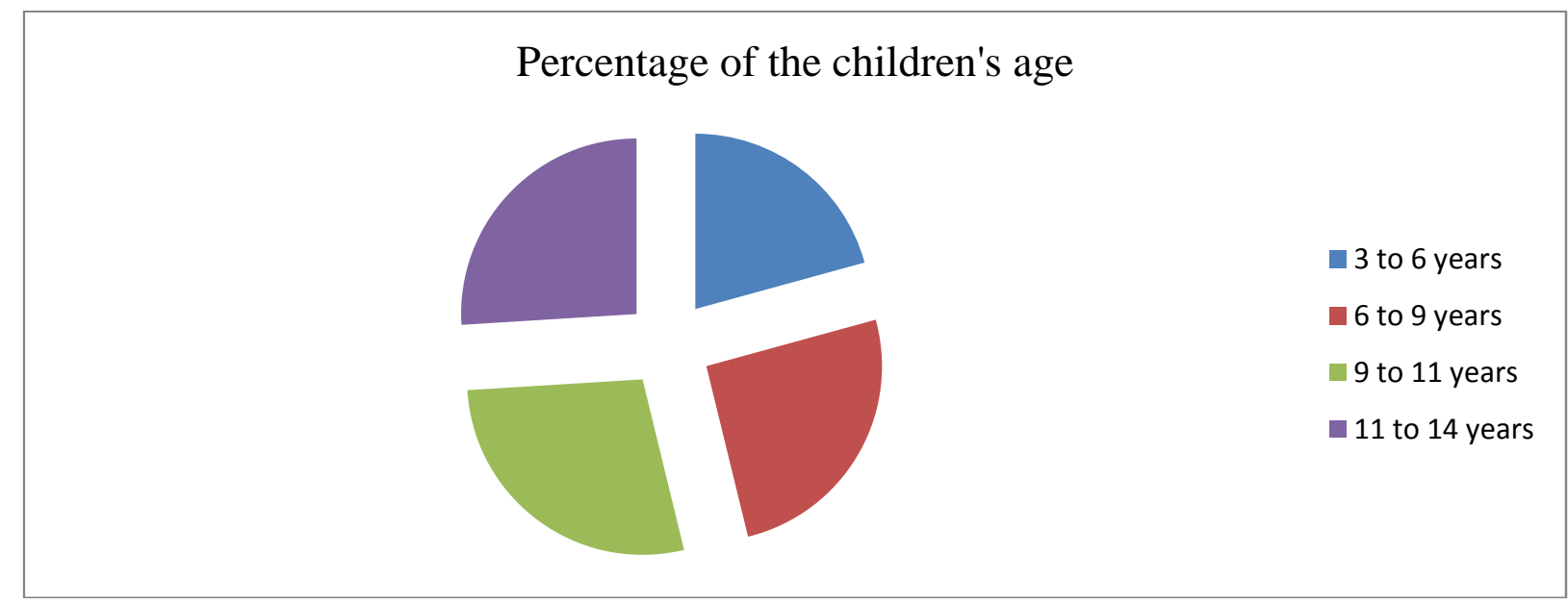

\section{Results}

Fig. 2. Survey participants' children age characteristics

We have Kolmogorov-Smirnov test (Fasano \& Franceschini, 1987) to verify the normality test where the null hypothesis was that the data are not normally distributed and details are shown in Table 1.

Table 1

The results of Kolmogorov-Smirnov test

\begin{tabular}{lcccc}
\hline Variable & Mean & Alpha & Level of significance & Null hypothesis \\
\hline Packaging children food products & 3.8049 & $5 \%$ & 0.117 & Accept \\
Parents' purchasing decision & 3.3706 & $5 \%$ & 0.143 & Accept \\
Priority of purchasing decision & 3.5183 & $5 \%$ & 0.070 & Accept \\
\hline
\end{tabular}

\subsection{The relationship between children food packaging and the parent's purchasing decision}

The first null hypothesis is as follows,

$$
\left\{\begin{array}{l}
H_{0}: \begin{array}{l}
\text { There is no positive relationship between packaging of children's food product and } \\
\text { parent's purchasing decision. }
\end{array} \\
H_{1}: \begin{array}{l}
\text { There is a positive relationship between packaging of children's food product and } \\
\text { parent's purchasing decision. }
\end{array}
\end{array}\right.
$$

The Spearman ratio is calculated as 0.319 with $\mathrm{P}$-value $=0.000$, which means we have enough evidence to reject the null hypothesis in favor of an alternative hypothesis.

\subsection{The relationship between children food packaging and the parent's priority purchasing decision}

The second null hypothesis is as follows, 
$H_{0}$. There is no positive relationship between packaging of children's food product and $H_{0}$ : parent's priority purchasing decision.

$H_{1}$ : There is a positive relationship between packaging of children's food product and parent's priority purchasing decision.

The Spearman ratio is calculated as 0.322 with $\mathrm{P}$-value $=0.000$, which means we have enough evidence to reject the null hypothesis in favor of an alternative hypothesis.

\subsection{The relationship between children food selection and the parent's purchasing decision}

Finally, the third null hypothesis is as follows,

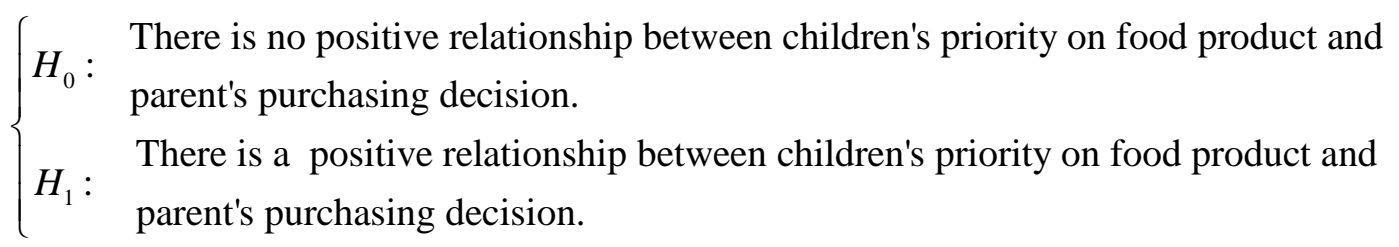

The Spearman ratio is calculated as 0.572 with $\mathrm{P}$-value $=0.000$, which means we have enough evidence to reject the null hypothesis in favor of an alternative hypothesis. In summary, we can say that packaging play an important role on attracting children's interest and create motivation for them to ask or in many cases force their parents to purchase a particular product. The more children are interested in purchasing a product, the more likelihood that parents buy a product. However, parents are the people who make the final purchasing decision and in case a product cannot attract parents, it cannot be located in their basket. Therefore, a packaging must not only attract children but also it must contain the necessary information to persuade parents. Note that a customer in food market makes his/her purchasing decision in less than three seconds. Therefore, packaging plays an essential role on providing necessary information for purchasing a product. There are also other studies, which indicate that children could influence more on their parents, as they get older. They normally put more efforts to convince their parents

\section{Conclusion}

In this paper, we have presented an empirical study on the relationship of children food packaging and parents' purchasing decision. The paper designed a questionnaire based on Likert scale, distributed 392 questionnaires among the target population of this survey who are one of the wellknown food chain suppliers named Shahrvand, and collected 381 filled questionnaires. There were three hypotheses for the proposed study of this paper. The first hypothesis assumed there was a meaningful relationship between packaging children's food characteristics and parents' intention on purchasing product. The second hypothesis investigated the relationship between children food packaging and the parent's priority purchasing decision and the third hypotheses examined the relationship between children food selection and the parent's purchasing decision. The results confirmed all three hypotheses and provided evidence that a suitable packaging for children's food product have important impact on parents' intention for purchasing products.

\section{Acknowledgment}

The authors would like to thank the anonymous referees for their construction comments on earlier version of this work. 


\section{References}

Becker, L., van Rompay, T.J.L., Schifferstein, H.N.K., \& Galetzka, M. (2011). Tough package, strong taste: The influence of packaging design on taste impressions and product evaluations. Food Quality and Preference, 22(1), 17-23.

Fasano, G., \& Franceschini, A. (1987) A multidimensional version of the Kolmogorov-Smirnov test. Monthly Notices of the Royal Astronomical Society, 225, 155-170.

Gofman, A., Moskowitz, H. R., \& Mets. T. (2010). Accelerating structured consumer-driven package design. Journal of Consumer Marketing, 27(2), 157-168.

Ho, C.T. B., \& Oh, K. B. (2009). An empirical study of the use of e-security seals in e-commerce. Online Information Review, 33(4), 655-671.

Ha, H.Y., Janda, S., \& Muthaly, S.K. (2010). A new understanding of satisfaction model in e-repurchase situation. European Journal of Marketing, 44(7/8), 997-1016.

Joreskog, K.G., \& Van Thillo, M. (1972). LISREL: A General Computer Program for Estimating a Linear Structural Equation System Involving Multiple Indicators of Unmeasured Variables. Princeton, NJ: Educational Testing Service.

Kauppinen-Räisänen, H., \& Luomala, H. T. (2010). Exploring consumers' product-specific colour meanings. Qualitative Market Research: An International Journal, 13(3), 287-308.

Levesque, R. (2007). SPSS Programming and Data Management: A Guide for SPSS and SAS Users, $4^{\text {th }}$ ed., SPSS Inc., Chicago Ill.

Morgado, A. (2008). Logoplaste: innovation in the global market, Management Decision, 46(9), 1414-1436.

Oliveira, J.C., Pinto, H.J., Zacarias, M.E., \& Hogg, T. (2010). New paradigm for patterns of home packaged food intake. British Food Journal, 112, 500-510.

Ogba, I.E., \& Johnson, R. (2010). How packaging affects the product preferences of children and the buyer behaviour of their parents in the food industry. Young Consumers: Insight and Ideas for Responsible Marketers, 11(1), 77-89.

Rundh, B. (2009). Packaging design: creating competitive advantage with product packaging. British Food Journal, 111(9), 988-1002.

Silayoi, P., \& Speece, M. (2007). The importance of packaging attributes: a conjoint analysis approach. European Journal of Marketing, 41(11/12), 1495-1517.

Silayoi, P., \& Speece, M. (2004). Packaging and purchase decisions. British Food Journal, 106(8), 607-628.

Vernuccio, M., Cozzolino, A., \& Michelini, L. (2010). An exploratory study of marketing, logistics, and ethics in packaging innovation. European Journal of Innovation Management, 13(3), 333-354.

Wells, L.E., Farley, H., \& Armstrong, G.A. (2007).The importance of packaging design for own-label food brands. Journal of Retail \&Distribution Management, 35(9), 677-690.

Williams, H., Wikstrom, F., \& Lofgren, M. (2008). A life cycle perspective on environmental effects of customer focused packaging development. Journal of Cleaner Production, 16(7), 853-859. 